\title{
Bridging difference - National and Organisational Adaptation for Responsible
}

Performance.

\author{
Ann J Davis, Carole Parkes, Pawan Budhwar \\ Work \& Organisational Psychology Group \\ Aston Business School \\ Birmingham \\ B4 7ET \\ United Kingdom
}

Address for correspondence: Dr Ann J Davis, Work \& Organisational Psychology Group, Aston Business School, Birmingham, B4 7ET, United Kingdom

Tel: 00441212043261

Email: a.j.davis@aston.ac.uk 


\begin{abstract}
This special issue draws together a selection of articles built around a theme of bridging difference. We argue that the effective transfer of learning across boundaries is crucial in enabling the dissemination of good, and ethical, HR practice. How that transfer might occur, with respect both to the mechanisms to enable or inhibit transfer, and the nature of learning that underpins that transfer, provides the focus of what is discussed here. This is framed against a concern for the nature and future of HRM, in particular its role in ensuring responsible organisational performance.
\end{abstract}

Keywords

International HRM, Knowledge Transfer, Emerging Markets, Ethics, Innovation 


\section{Introduction}

This special issue arose from the11th International HRM conference held in June 2010. The conference focus on emerging markets served to remind us all that openness to new approaches and perspectives can only enhance the ability of the global HR community to develop and adapt. Learning from existing experience and exploring the extent to which that learning can carry across boundaries is the focus for the papers presented here. As we hopefully emerge from near global recession, what have we learned about what we as a profession and a discipline should retain and nurture, and what might limit our ability to share and develop that learning in developing contexts?

Learning, and the transferability of learning, emerged as a key theme for this special issue. While research has focused on the similarities and differences between approaches to HRM both in philosophy and practice worldwide, the debate about what works is increasingly contextualised. Here we focus on changing HR to bring about improvement, focussing on which specific contingencies can impact positively or negatively on the transfer of knowledge and learning across borders. Crossing boundaries therefore is central to the papers presented here.

The increasing dominance of a best practice model for HR effectiveness provides a starting point for discussion. We are aware of the range of studies which have tended increasingly to support a best practice model centred on high performance work systems (Aryee, Walumbwa, Seidu, \& Otaye, 2012; Sun, Aryee, \& Law, 2007; Takeuchi, Lepak, Wang, \& Takeuchi, 2007; Way, 2002; Huselid, 1995). Still, the inherent variety in HR practice worldwide currently implies that achieving such best practice requires substantial change to current practice and local interpretation of the meaning of the constituent elements of HPWS may be necessary. The question therefore becomes how do we bridge these differences? If we are to accept a best practice model of HR, what change is needed, and in particular what learning is needed to bring about such change?

The literature on organisational learning provides an integrating view of knowledge development within organisations, however examples of effective organisational learning and how that learning affects overall performance are relatively rare. Across a broad range of contexts does the learning organisation develop in a similar fashion or does variation in cultural and institutional background impact on process, prioritising some processes over others?

At a more practical level, how do we transform tacit knowledge and understanding of learning and innovation into practice? The principle of equifinality (von Bertalanffy 1968) tells us that there are many ways to achieve given end states, however what these mechanisms might be and the conditions under which some are preferable or more effective to others remain to be established? Structural change, systems theory, employee involvement and organisational development all appear to offer some value in relation to obtaining desired outcomes, including enhanced performance, wellbeing and innovation. Recently, there has been considerable development in the literature on situated learning and communities of 
practice (Cabrera \& Cabrera, 2005, Wenger, 2000, Wenger, McDermott \& Snyder, 2002) which offer a further route for the transformation of learning into practice. These can serve as a guiding mechanism both for generating new knowledge and for disseminating existing knowledge to previously excluded or marginalised groups. This however begs a further question in relation to how do such COPs develop. While such communities may develop organically, the nature of exclusion and marginalisation suggests that, in some domains, more active promotion or mediation of such communities may be necessary. What these intermediate mechanisms might look like and how they might operate gives rise to further opportunities for research.

While we may develop views on how learning is transformed into practice, we still have concerns about what is transferable where, and indeed what is desirable to transfer. If we regain and refocus our role in this respect, then the differences in values and institutional arrangements internationally pose challenges for the transfer of learning. The boundary conditions which prevent or facilitate the international adoption of HR best practice bear closer examination. The routes through which HR practice is transported across boundaries are varied. Different institutional and cultural contexts may impact on what is transferable, while the mechanics of HR knowledge transfer itself is also in question. Rarely is it HRM specialists who are expatriated within international business, so the effective communication and implementation of HQ strategy may be left to non-specialists whose core responsibilities lie in their own area of technical expertise. The increasing diversity of international working and global careers serves further to complicate the process of achieving a coherent strategy.

One core concern, in light both of the economic downturn of the last several years and the reliance on non-specialist staff to communicate HR strategy, must be the values that HRM seeks to instil and its impact on the ethics of organisations. While contemporary models of HRM emphasise its potential in adding value to organisations, there is a danger in its application that it overlooks the human component of the practice at the expense of corporate gain. Our quest for legitimacy and a seat at the "top table" has on occasion compelled practitioners to demonstrate an aggressive profit maximisation strategy, which not only undermines the inherent value of the people within the organisation, but has on occasion resulted in practices which actively (although unintentionally) encourage unethical, and counterproductive, behaviours. In an era where corporate social responsibility is increasingly recognised as a central component of organisational philosophy, for example through the “triple bottom line” (Brown, Dillard \& Marshall. 2009) of people, planet and profit, can we regain ground as the guardians of corporate ethics, thus reinforcing the relevance of HRM while also contributing to valued organisational outcomes?

Cultural and institutional variation impacts on the propensity of HR practice to become embedded in new and developing contexts. In emerging economies the institutional arrangement are likely to be very particular, grounded in the history of the country. Cultural variation also we know affects the propensity to adopt HR practice. However it is important to recognise that where economies are developing, the changes in values ad attitudes may occur at a different rate for different constituencies. Changing a political system may occur 
overnight, changing the values and attitudes against which it has to operate is a more long term challenge.

\section{The content of this special issue.}

This above discussion sets the stage for the issues reflected in this special issue. First a group of papers explores the extent to which learning and particularly situated learning enables HR to adapt appropriately to context and to influence organisational outcomes. The second theme relates to the transferability of knowledge and the boundary conditions which impact on that knowledge transfer. Here we look at the conditions affecting process of transfer, are some practices more transferable and what mechanisms enable or inhibit it. Within this however we also need to ask questions about what is valuable in HR practice, looking to the future of the profession while drawing lessons from its history. The ethics of HRM, and the role of HRM in promoting ethical organisations is core to our view of the domain and the profession. Are there core "non-negotiable" values for HR and if so, can we reinforce these values in the current economic landscape? Finally, we explore specific contextual issues which come into play; both cultural, structural and institutional.

Taking these themes in turn, the importance of context and shared experience of learning to promote innovation emerges in three papers included in this issue. At a multinational level, Shipton, Zhou and Mooi provide support for the capability-building role of organisational learning, and the mediational influence of innovation on performance. Perhaps surprisingly, their results suggest more similarities than differences in the sample of nearly six thousand organisations drawn from 14 different countries. A developmental orientation, an HRM focus which attends to the needs of staff and a customer-facing remit for the business as a whole combine to generate a second order learning organisation construct (Hult et al., 2002). The mediational role of innovation between learning organisation and organisational performance remained remarkably constant across the sample, only three countries reporting a better fit of the data through a partial mediation model.

Scully and her colleagues take a different approach to SHRM, learning and innovation. They report on two qualitative studies seeking to convert tacit to explicit knowledge to generate innovative behaviour in health care environments (Nonaka \& Takeuchi, 1995). The different HR approaches adopted in the cases provide alternative routes for SHRM to capture and surface tacit knowledge; the first through structural redesign and the second via the introduction of greater levels of involvement and team integration.

Theodorakopoulos et al base their study of intermediation and the development of communities of practice and innovation in procurement in a situated learning theory framework. Taking an action research approach (Nowotny, Scott and Gibbons 2003), they report on work designed to enable entrepreneurs among the ethnic minority business owners to forge more effective links with broader procurement networks. The communities of practice which develop amongst the stakeholders through the intermediaries' intervention facilitate more socially responsible and inclusive networks of procurement and supply. 
The second theme of transferring knowledge into new contexts, or embedding it in existing ones, is addressed by three further papers in this issue. Mellahi et al explore the circumstances enabling the transfer of HR practices between head office and subsidiaries within Multinational Enterprises. Acknowledging both the institutional and cultural milieu of the subsidiaries, they argue that there will be variation in the ease with which different HR practices may transfer, dependent on the ease with which the practices can be managed (Björkman and Lervik 2007) and their relationship to core organisational values and local institutional imperatives (Gunnigle et al. 2002).

Both Chang and Smale and Baruch and colleagues highlight the complexity inherent in modern international staffing decisions and the assumed role for international staff in communicating and embedding HR practice. Baruch and colleagues provide an overview and analysis of the nature of international working which has a bearing on several of the articles features here. Recognising the variety of international work configurations, they identify seven dimensions of global career which opens up many discussions for policy makers, organisations and individuals shaping and managing mobile careers. Their helicopter view of global careers provides a platform for the development of more tailored international mobility and global career systems.

Chang and Smale focus on the role of expatriates as a vector for HR practice. They highlight that while expatriate appointments are often viewed as a key vehicle for the transportation of core values, practises and know-how across borders, rarely are expatriates HR professionals. They identify that the absorptive and disseminative capacities of non-HR specialist expatriates with respect to the transfer of HR knowledge are affected by their ability and motivation to engage with the HR agenda. While in some cases there was a lack of ability in the domain, the issue of motivation confirms an on-going concern over the priority given to HR policy and practice.

The issue of the centrality and significance of HR practice is at the core of the paper by Parkes \& Davis. They review the relative silence of the profession in light of the turbulence of recent years and seek to address a question posed by a number of professional bodies where was HR when the practices which contributed to the GFC were being allowed to run their course. Drawing on social psychology they compare alternative explanations of the reasons for HR's ineffectiveness, concluding that perhaps a return to its roots as a valuedriven process with concern of ethical treatment at work might offer a more sustainable model of not just HR but business practice generally moving forward.

The final papers explore the contextual issues relating to the transfer of HR knowledge, particularly in relation to developing economies. Horowitz focusses on the experience of South Africa and the challenge of retaining and developing sufficient talent to enable this economy to develop effectively. He adopts a labour market approach, coupled with institutional analysis to untangle some of the challenges facing the country affected by significant shortages of intermediate and high level skills. 
Woldu and colleagues again focus on emerging markets but explore variation in both inter and intra country cultural values. Drawing on data collected from Turkey and Poland, they reflect on the internal cultural dynamics and their likely impact on employment strategy. Perhaps unsurprisingly, significant variation in cultural values were observed between countries, however the variation within each country, according to a range of demographic indicators, also asks questions of HRM practice. Countries in transition face challenges not only of adjusting to changing employment practices and attitudes, but also that the pace and acceptability of such adjustment may vary among groupings within that context.

Bridging difference and the processes and mechanisms that may seek to achieve it is not proposed an argument for uniformity. We seek through this collection of papers to highlight some of the challenges existing in the IHRM domain and suggest some directions for further research focusing on process and mechanisms to bring about change. These changes perhaps need to reflect not just on the outcomes IHRM practice, but on the practice itself.

Aryee, S., Walumbwa, F. O., Seidu, E. Y. M., \& Otaye, L. E. (2012). Impact of highperformance work systems on individual- and branch-level performance: Test of a multilevel model of intermediate linkages. Journal of Applied Psychology, 97(3), 667.

Bertalanffy, Ludwig von, General Systems Theory, 1968

Brown, D, Dillard, J \& Marshall, S 2009, 'Triple Bottom Line: A Business Metaphor for a Social Construct'. J Dillard, M King \& V Dujon (eds), in: Understanding the social dimension of sustainability. Taylor and Francis, pp. 211-230.

Björkman, I. and Lervik, J.E. (2007). Transferring HRM practices within multinational enterprises. Human Resource Management Journal, 17: 320-335.

Cabrera, E.F. and Cabrera, A. (2005), Fostering Knowledge Sharing Through People Management Practices, International Journal of Human Resource Management, 16, 5, 720-735.

Gunnnigle, P., Murphy, K.M., Cleveland, J., Heraty, N., and Morley, M. (2002). Localization in human resource management: Comparing American and European multinational corporations. Advances in International Management, 14: 259-284.

Hult, R., G, Ketchen, D. and Nichols, E. (2002). 'An examination of cultural competitiveness and order fulfilment cycle time within supply chains'. Academy of Management Journal, 45, 3, 577-586

Huselid, M. (1995). The impact of human resource management practices on turnover, productivity, and corporate financial performance. Academy of Management Journal, 38(3), 635-672.

Nonaka, I., and Takeuchi, H. (1995), The knowledge- creating company: How Japanese companies create the dynamics of innovation, New York and Oxford: Oxford University Press.

Nowotny, H., Scott, P., and Gibbons, M. (2003), 'Introduction: “Mode 2'” Revisited: The New Production of Knowledge’, Minerva, 41, 3, pp. 179-194. 
Sun, L, Aryee, S., \& Law, K. S. (2007). High-performance human resource practices, citizenship behavior, and organizational performance: A relational perspective. Academy of Management Journal, 50(3), 558-577.

Takeuchi, R., Lepak, D. P., Wang, H., \& Takeuchi, K. (2007). An empirical examination of the mechanisms mediating between high-performance work systems and the performance of Japanese organizations. Journal of Applied Psychology, 92(4), 1069.

Way, S. A. (2002). High performance work systems and intermediate indicators of firm performance within the US small business sector. Journal of Management, 28(6), 765785.

Wenger, E. (2000), 'Communities of Practice and Social Learning Systems', Organization, 7, 2, $225-246$.

Wenger, E., McDermott, R., and Snyder, W.M. (2002), Cultivating Communities of Practice, Boston, MA: Harvard Business School Press. 